\title{
THE RANCH LAKE INDICATOR MINERAL TRAIN: SINGLE OR MULTIPLE SOURCES?
}

\author{
Antonio Gonzales ${ }^{1}$, Michael Baumgartner ${ }^{2}$ and Karina Gelo ${ }^{1}$ \\ ${ }^{l}$ BHP Billiton Diamonds Inc. Canada; ${ }^{2}$ Mineral Services, South Africa;
}

\section{INTRODUCTION}

The Ranch Lake kimberlite pipe is located centrally on the Slave Craton of Canada and is approximately $75 \mathrm{~km}$ northwest of the Ekati Diamond Mine ${ }^{\mathrm{TM}}$ (Figure 1). The kimberlite is enigmatic in that it occurs as a single large isolated pipe $(\sim 11 \mathrm{Ha})$. It has an indicator mineral train which has been traced for at least $40 \mathrm{~km}$ down-ice. Most kimberlites occur in clusters, and the initial indicator dispersion results appeared to be consistent with multiple sources. A previous study of the Ranch Lake indicator mineral train concluded that the east to west trending dispersion is derived from a single source (McClenaghan et al., 2000). The study was based largely on garnet textures, relative abundance of indicator minerals and soil geochemistry. The mineral compositions of grains in the dispersion were compared by McClenaghan et al. (2000) to the Ranch Lake kimberlite, incorporating the entire dispersion rather than as an evaluation of possible down-ice variation. The current study was designed to evaluate the potential for multiple sources by evaluating variations at various distances down-ice of Ranch Lake. Consistency in indicator mineral abundance, mineral composition and mineral textures would indicate a single source but variations in input down-ice maybe suggestive of multiple sources.

\section{METHOD}

A total of 27 till samples were selected for this study and are considered to be representative of the Ranch Lake dispersion. The samples were collected along north-south lines, perpendicular to the regional ice flow direction. The samples were derived from shallow

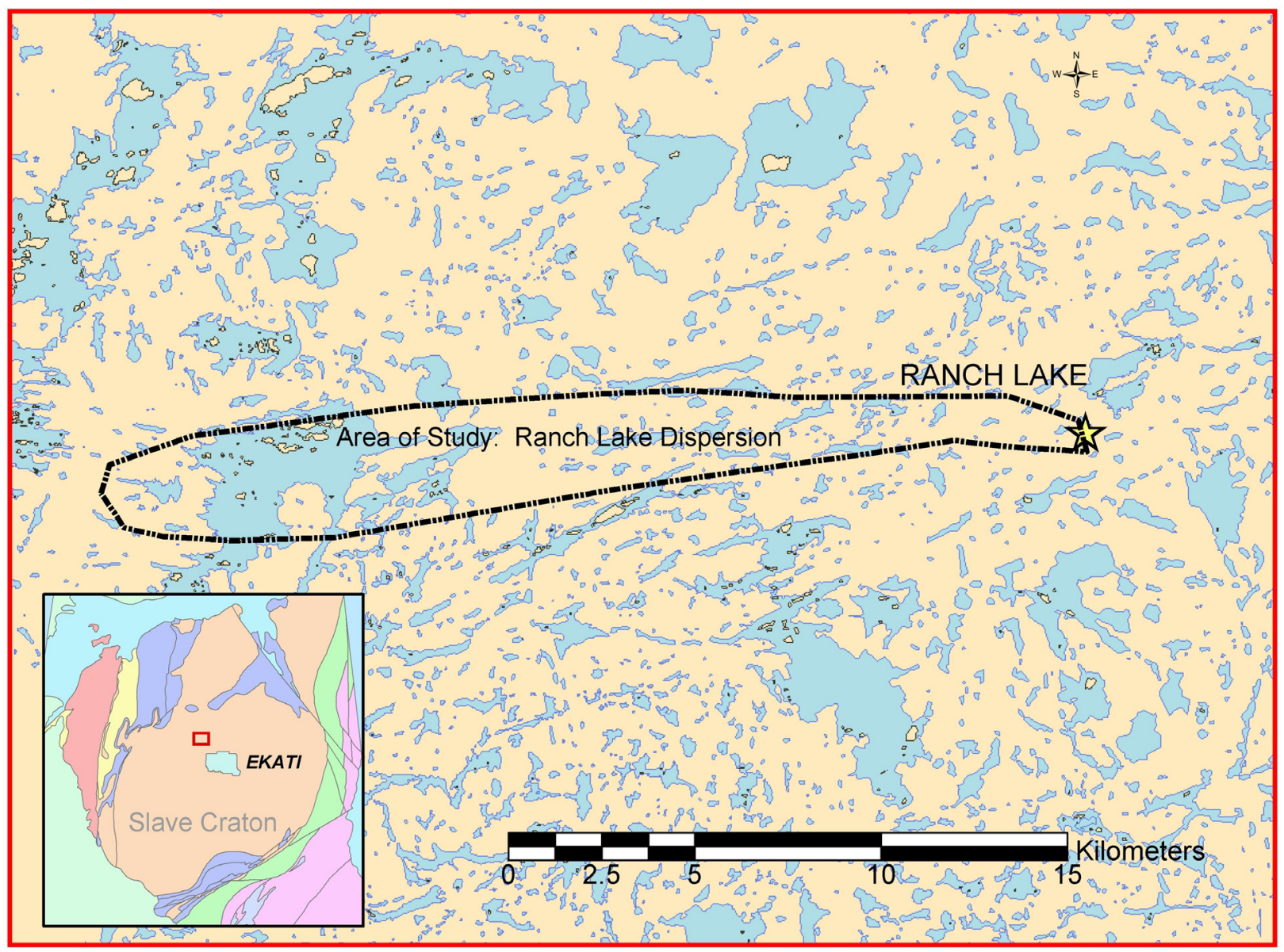

Figure 1: Map showing the location of the Ranch Lake kimberlite and extent of the indicator mineral dispersion train. 
(between 30 and $60 \mathrm{~cm}$ ) hand-dug pits in mud-boils within the active layer. Approximately $25 \mathrm{~kg}$ of sample material was wet-screened in the field to -6 mesh reducing the sample size to $10 \mathrm{~kg}$ for processing. Concentrates from these samples were processed in order to obtain representative suites of indicator minerals from three different size fractions (250500um, 500-1000um and 1000-2000um). The data were normalised to the original sample weight of $10 \mathrm{~kg}$, providing the most reliable possible estimate of abundance of fine $(0.25-0.5 \mathrm{~mm})$, medium $(0.15-1$ $\mathrm{mm})$ and coarse $(1-2 \mathrm{~mm})$ indicator minerals in all submitted samples. In addition, grain surface textures were documented and selected mineral grains were analysed.

Normalised picking results were investigated using geographical information systems (GIS) and statistical software to identify any trends that may be present and to establish evidence for additional possible sources. Mineral abundances were examined on the GIS using a variety of visualization techniques including scaled symbols and gridding and contouring.

Surface texture descriptions were completed on a total of 1513 medium and coarse indicator mineral grains. Additionally, the weight of each mineral type in the medium and coarse fractions was determined to permit calculation of average grain weight per size fraction. The surface texture data were also evaluated using the GIS. Variation in total and average weight of grains in the medium and coarse size fractions and possible trends in the detailed surface textural characteristics of grains were documented. Emphasis was placed on discriminating possible changes in the average proportions of grains with high interest surface textures that could reflect input of indicators from a proximal source.

A total of 928 grains were analysed at the Mineral Services Diamond Laboratory, including 489 garnets, 171 chromites, 176 chrome diopsides, 59 ilmenites, 11 titano-magnetites and 14 other non-kimberlitic grains. The selected indicator minerals were analysed for major and minor elements using energy dispersive (ED) and wavelength dispersive (WD) spectrometers (Oxford Instruments) attached to a LEO 1450 Scanning Electron Microscope (SEM).

\section{RESULTS}

GIS and statistical evaluation indicates variations in the abundance of purple garnet, chrome diopside, chromite and ilmenite with distance from the Ranch Lake kimberlite. Distinct peaks in the abundance of various mineral types, particularly purple garnet and chrome diopside, occur at distances of $8-10 \mathrm{~km}, 17 \mathrm{~km}$ and 21 $\mathrm{km}$ down-ice of Ranch Lake (Figure 2 and 3). The relative abundance of purple garnet and chrome diopside, are consistent and show little variation with distance from Ranch Lake. In contrast, the relative abundance of chromite and ilmenite, which are respectively, one and two orders of magnitude less than peridotitic garnets, change and increase particularly at a distance of about $17 \mathrm{~km}$ down-ice of Ranch Lake. This is shown in Figure 4.

The average weight of the medium and coarse grains was evaluated as a potentially useful indicator of proximity to source. However, little variation was detected along the dispersion train for most of the mineral types with the exception of medium ilmenite and coarse chromite which, show distinctive increase in average mineral weight approximately 15 to $17 \mathrm{~km}$ down-ice of Ranch Lake.

Kelyphite rimmed garnets are common in the medium and coarse grains along the length of the Ranch Lake dispersion train and little variation in the extent of kelyphite preservation is evident with distance from Ranch Lake. McClenaghan et al (2000), on the other hand, observed a decrease of fine $(0.25$ to $0.5 \mathrm{~mm})$ pyrope grains with kelyphite rims and increase of pyrope garnets with orange peel texture (sub-kelyphitic) with increasing distance down-ice. This trend could not be verified in the current study since surface texture descriptions were not undertaken on the fine-grained minerals recovered in this study.

In the samples collected for this study, perovskite mantled ilmenite was found to be present in only one sample located $17 \mathrm{~km}$ down-ice of Ranch Lake. The occurrence may not be of significance since ilmenites are rare within the dispersion, and are also present in the Ranch Lake kimberlite in very low abundance. 


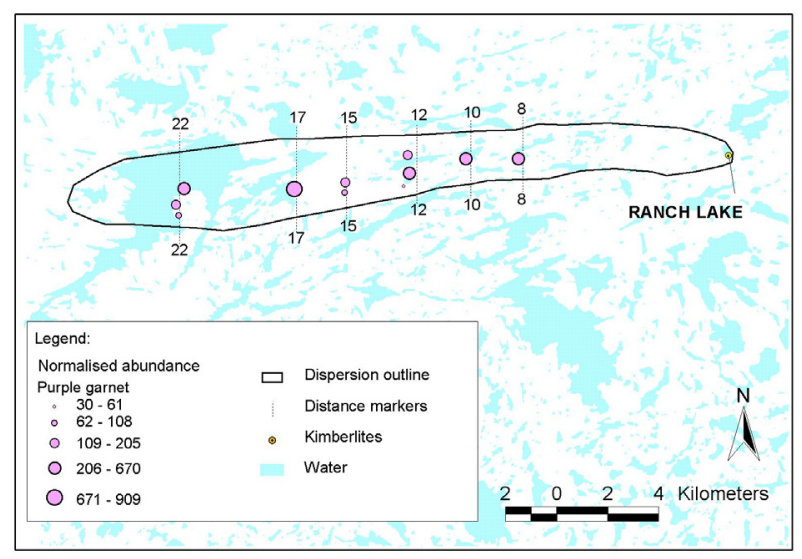

Figure 2: Map showing the relative abundance of purple garnet for selected samples collected in the Ranch Lake dispersion train.

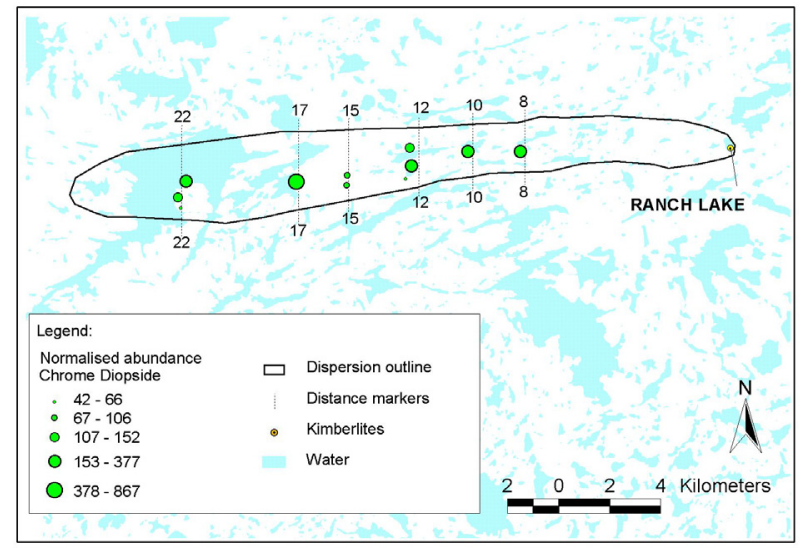

Figure 3: Map showing the relative abundance of chrome diopside for selected samples collected in the Ranch Lake dispersion train.

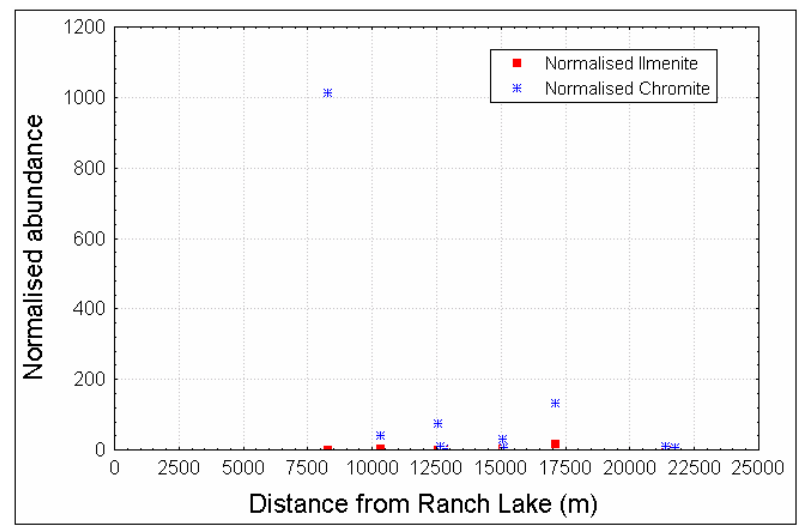

Figure 4: Graph showing the relative abundance of ilmenite and chromite for selected samples collected in the Ranch Lake dispersion train.

The mineral abundance data and surface texture features of the medium and coarse grains discussed above suggest that there is a distinct possibility of additional undiscovered sources to be contributing grains to the Ranch Lake dispersion. The evidence for an additional contribution is particularly strong at a distance of approximately 15 to $17 \mathrm{~km}$ down-ice of the Ranch Lake kimberlite. In order to further assess this possibility, an evaluation of the variation in mineral composition down ice was undertaken. Little down-ice variation is observed in the composition of chromite, ilmenite, low chrome eclogitic and megacryst garnets, high-chrome garnets and chrome diopside compared with equivalent minerals from the Ranch Lake kimberlite This is illustrated in the mineral composition plots for peridotitic garnets analysed from samples at increasing distance from the Ranch Lake kimberlite (Figures 5 through 7), along with the mineral compositions of representative peridotitic garnets from the kimberlite itself (Figure 9).

\section{8-10km down-ice}

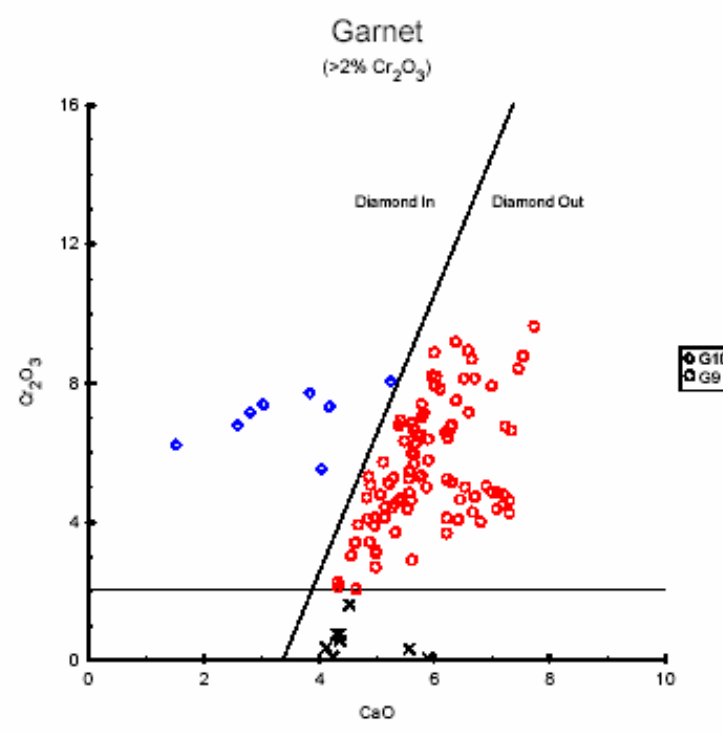

Figure 5: $\mathrm{Cr}_{2} \mathrm{O}_{3}$ versus $\mathrm{CaO}$ plot showing the composition of garnets recovered between 8 and $10 \mathrm{~km}$ down-ice of the Ranch Lake kimberlite. 


\section{$15-17 \mathrm{~km}$ down-ice}

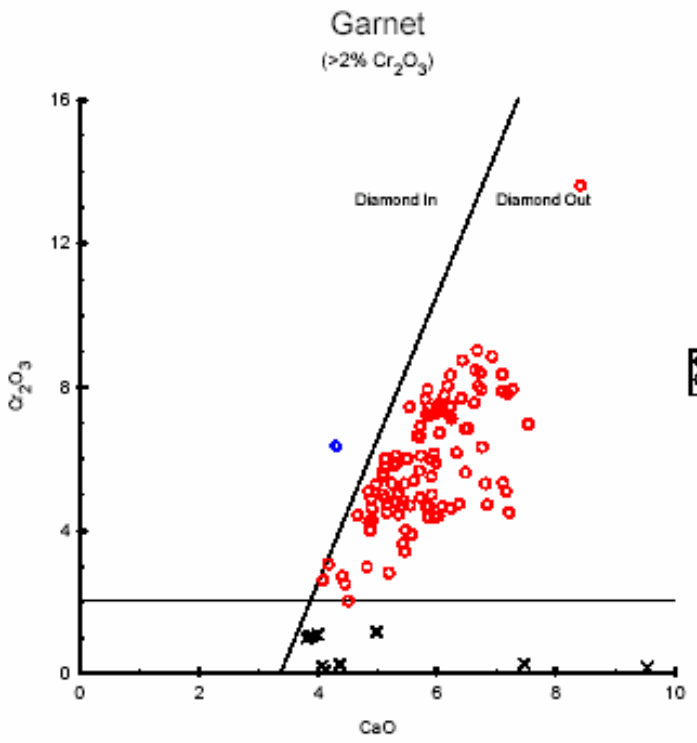

Figure 7: $\mathrm{Cr}_{2} \mathrm{O}_{3}$ versus $\mathrm{CaO}$ plot showing the composition of garnets recovered between 15 and $17 \mathrm{~km}$ down-ice of the Ranch Lake kimberlite.

\section{$22 \mathrm{~km}$ down-ice}

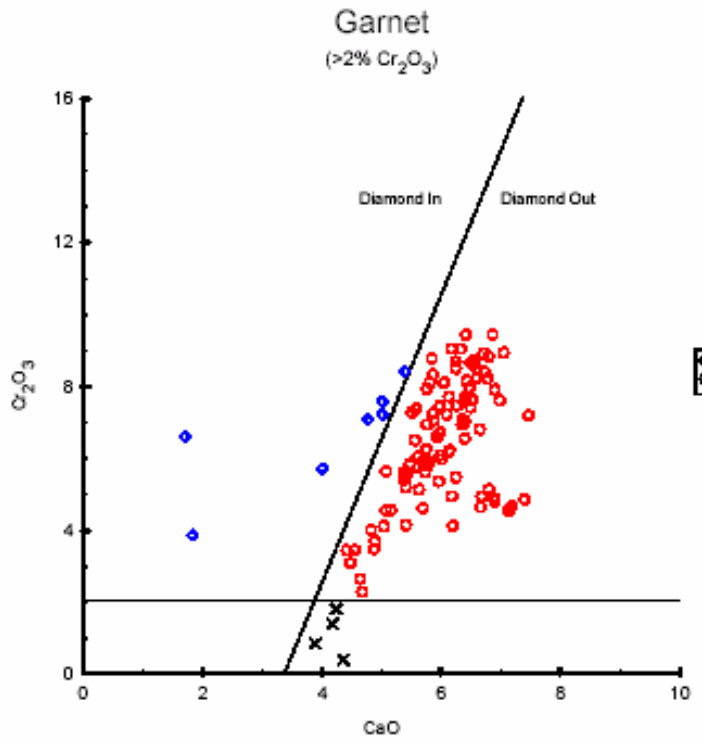

Figure 8: $\mathrm{Cr}_{2} \mathrm{O}_{3}$ versus $\mathrm{CaO}$ plot showing the composition of garnets recovered $22 \mathrm{~km}$ down-ice of the Ranch Lake kimberlite.

\section{Ranch Lake Kimberlite}

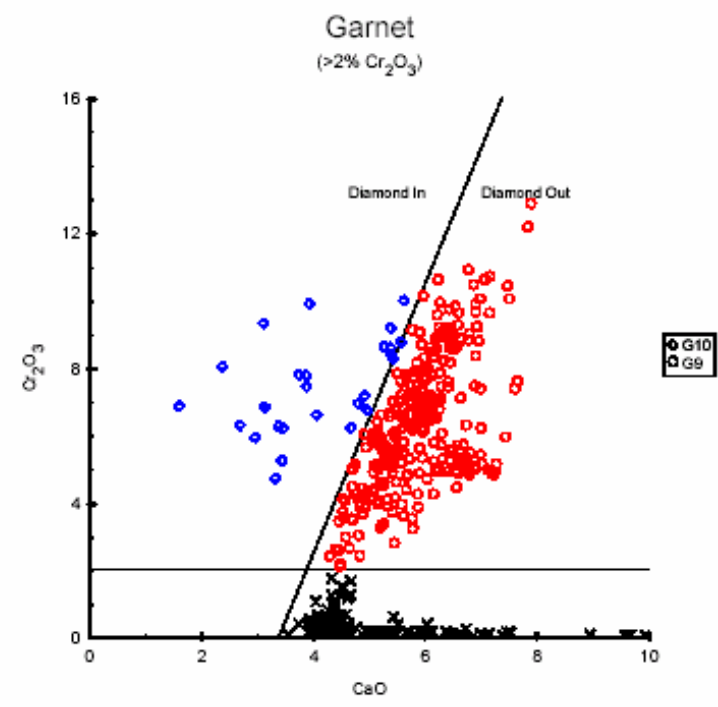

Figure 9: $\mathrm{Cr}_{2} \mathrm{O}_{3}$ versus $\mathrm{CaO}$ plot showing the composition of garnets recovered from the Ranch Lake kimberlite.

\section{DISCUSSION AND CONCLUSIONS}

Erratic variations in mineral abundance occur along the Ranch Lake dispersion train, in particular, there are increases in abundance of purple garnet and chrome diopside at 8-10 km, $17 \mathrm{~km}$ and $21 \mathrm{~km}$ from Ranch Lake. The increased abundance of chromite and ilmenite at a distance of $17 \mathrm{~km}$ and may also be significant. Both McClenaghan et al (2000) and Cookenboo (1994) suggest that large blocks of kimberlite may have been excavated, glacially transported and deposited relatively intact from the Ranch Lake body. Cookenboo (1994) however believes that the amount of material required to produce the observed anomalies would have to be as large as Ranch Lake itself and considered such an explanation as an unlikely scenario. The same author further speculated that there are potentially 4 or 5 additional distinctive sources. Supporting this argument is the work of Thomas (2001) who advocated a multiple sources scenario by suggesting that dispersal trains of this length are unusual and that the crater facies material that comprises Ranch Lake is unlikely to be preserved during long distance transport. In contrast, harder, more competent hypabyssal facies kimberlite may tend to produce dispersion trains of greater length than crater facies kimberlite (Thomas, 1998). 
McClenaghan et al, (2000) suggested that variations in the abundance of indicator minerals may be attributed to an undiscovered source west of Ranch Lake but that this is not consistent with pyrope compositions and relative abundance data. Other explanations offered by McClenaghan et al, (2000) and Thomas (2001) for the trends in the dispersion train include differential erosion by ice sheets at variable times, lag deposits producing anomalies down-ice from the source in areas of thick till, and winnowing of material resulting in indicator mineral enrichment. . Generation of the anomaly from lag deposits is inconsistent with the data as the anomalies occur many kilometers down-ice of Ranch Lake, requiring till thickness of thousands of meters. Additionally, enrichment of minerals by winnowing is contradicted by good kelyphite preservation at sites of increased indicator mineral abundance. The high degree of kelyphite preservation is also in disagreement with increased attrition of minerals in the till (Cookenboo, 1994).

In this study, it is demonstrated that mineral compositions and the relative abundance of mineral types (high-Cr peridotitic garnets, low-Cr eclogitic and megacryst garnets, chromite, ilmenite and chrome diopside) in the dispersion till samples are very similar to those from samples of Ranch Lake kimberlite. Despite careful examination of the data for subtle down-ice variations, none were found.

Thus, the results of this study are consistent with the single source theory of McClenaghan, et al. (2000). While, additional undiscovered sources with very similar mineral compositions to the Ranch Lake kimberlite could theoretically be contributing to the Ranch Lake mineral train, there is no clear evidence to suggest this. In addition, should such sources be present, it would be extremely difficult to find on the basis of mineral abundance and composition due to the masking effect of this distinctive dispersion. Intensive exploration efforts to date have failed to locate any additional pipes in the Ranch Lake area.

\section{REFERENCES}

Cookenboo, H., 1994. Ranch Lake Train: A dispersion apparently produced by multiple sources in a kimberlite field. Unpublished confidential report prepared for Lytton Minerals.

Dredge, L.A., Kerr, D.E., Kjarsgaard, R.D., Knight, R.D. and Ward, B.C., 1997. Kimberlite indicator minerals in till, central Slave Province, Northwest Territories. Geological Survey of Canada, Open File 3426.

Klassen, R.A., 1999. A Quaternary geological perspective for geochemical exploration in glaciated terrain in Drift exploration in glaciated terrain. Short Course April 10, 1999. Sponsored by the Association of Exploration Geochemists.

McClenaghan, M.B., Ward, B.C., Kjarsgaard, I.M., Kjarsgaard, B.A., Sirling, J.A.R., Kerr, D.E., and Dredge, L.A., 2000. Indicator mineral and till geochemical dispersal associated with the Ranch Lake kimberlite, Lac de Gras region, Northwest Territories. Geological Survey of Canada. Open File 3924, 2000.

Millar, J.K., 1984. Model for clastic indicator trains in till. In Prospecting in areas of glaciated terrain. Institution of Mining and Metallurgy. London, pp. 69-77.

Millard, M.J., 1993. The Ranch Lake dispersion train: preliminary observations. Saskatchewan Research Council. Publication R-1210-8-C-93, 7 pages.

Thomas, R.D., 1998. Quaternary geology of the Ekati Mine property, Lac de Gras area, Northwest Territories. Unpublished report prepared for BHP Diamonds Inc.

Thomas, R.D., 2001. Quaternary geology of the Bio property, Northwest Territories. Unpublished report prepared for BHP Billiton Diamonds Inc.

Contact: antonio.m.gonzales@bhpbilliton.com 